monary radiological scrutiny as in hospital. We would therefore not know if any of these children had small areas of collapse, which could not be detected clinically and had not cleared up completely, giving them a permanently reduced FVC. It might be argued that the younger the child the greater would be his difficulty in understanding how to do the lung function test. Although it took more patience with the younger ones, we succeeded in testing satisfactorily all but 64 children. We found that the lung function of the index children who had had respiratory complications after whooping cough in the 1977-9 epidemic was within normal limits. There were no children with evidence of bronchiectasis.

We thank the three research nurses, Mrs A Cunningham, Mrs A C Roberts, and Mrs M Wilson, and the two unit secretaries, Mrs A Griffiths and Mrs P Saunders, for their unfailing efforts to make this study a success; Mrs P McCarthy and Mrs M McDermott, of the Medical Research Council Pneumoconiosis Research Unit at Llandough Hospital, Penarth, for their guidance in the method of lung function testing; and Mrs M F Clay for teaching the nurses to use the spirometer and for repairing the instruments when these became faulty. We also thank Dr P D Oldham, chairman of the executive committee of the MRC Pneumoconiosis Unit, Penarth, for his invaluable help during the study and detailed comments on the main report. Finally, this unit is grateful to the Department of Health and Social Security for the generous grant, without which this study would not have been possible.

\section{References}

1 Osler $\mathrm{W}$. Whooping cough. In: The principle and practice of medicine. New York, London: D Appleton and Company, 1918

Lees AW. Atelectasis and bronchiectasis in pertussis. Br Med 7 1950;ii:1138-41

Nicholson DP. Pulmonary collapse in pertussis. Arch Dis Child 1949;24:29-40. ames U, Brimblecombe FSW, Weston Wells J. The natural his
collapse in childhood. Q $\mathcal{F}$ Med 1956;97(NS XXV):121-36.
6 Islur J, Anglin CS, Middleton PJ. The whooping cough syndrome: a continuing pediatric problem. Clin Pediatr (Phila) 1975;14:171-6.

7 Johnson IDA, Lambert HP, Anderson HR, Patel S. Respiratory morbidity and lung function after whooping cough. Lancet 1983;ii:1104-8.

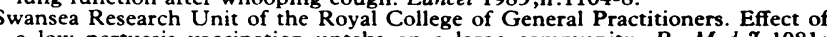
a low pert $282: 23-32$.

Conover WJ. Some reasons for not using the Yates continuity correction on $2 \times 2$ contingency tables. Fournal of the American Statistical Association 1974 69:374. 10 Sokal RR, Rohlf FJ. Biometry. 2nd ed. San Francisco: W H Freeman and Co,

11 Cox DR, Snell EJ. A general definition of residual. fournal of the Royal Statistical

Society $B$ 1968;30:248.
12 Oldham PD, Cole TJ. Estimation of the FEV,. Thorax 1983;38:662-7 Cole TJ. Linear and proportional regression models in the prediction of ventilatory function. Fournal of the Royal Statistical Society $A$ 1975;138:297-338. pertussis inoculation. Arch Dis Child 1974:49:46-9.

Jeavons PM. Whooping cough immunisation policy. Lancet 1975;ii:811.

16 Stewart GT. Reactions to pertussis vaccine. Lancet 1983;i:1217-8.

17 Stewart GT. Pertussis vaccine-benefits and risks. N Engl f Med 1980;302. 634 .

18 Stewart GT. Benefits and risks of pertussis vaccine. N Engl F Med 1980;303: 1004

19 Department of Health and Social Security, Joint Committee on Vaccination and Immunisation. Review of the evidence on whooping cough vaccination. London: HMSO, 1977.

20 Joint Committee on Vaccination and Immunisation of the Central Health Service Council and the Scottish Health Service Council and the Scottish
Health Service Planning Council. Whooping cough vaccine. Br Med $\mathcal{J} 1975$; iii : 687

21 Noah ND. Attack rates of notified whooping cough in immunised and unimmunised children. Br Med $\mathcal{f} 1976 ; 1: 128$.

22 McKendrick MW, Gulley PR, Geddes AM. Protection against pertussis by immunisation. $\mathrm{Br}$ Med f $1980 ; 281: 1390-1$.

23 Williams WO. How to do collaborative research $B r$ Med f 1982;285:480-2.

4 Speight ANP, Lee DA, Hey EN. Underdiagnosis and undertreatment of asthma in childhood. $B r$ Med $71983 ; 286: 1253-6$

25 Lee DA, Winslow NR, Speight ANP, Hey EN. Prevalence and spectrum of

Gregg I. Epidemiological aspects. In: Clarke TJH, Godfrey S, eds. Asthma. 2nd ed. London: Chapman and Hall, 1983:242-84

27 Hull $D$. Interpretation of the contraindications to whooping cough vaccination. Br Med f 1981;283:1231-3.

8 Department of Health and Social Security, Joint Committee on Vaccination and Immunisation. Immunisation against infectious disease. London: HMSO, 1984 9 Badr-El-Din MK, Aref GH, Mazloum $\mathrm{H}$, et al. The beta-adrenergic receptors

in pertussis. F Trop Med Hyg 1976;79:213.
30 Szentivanyi A. The beta-adrenergic theory of the atopic abnormality of bronchial asthma. Fournal of Allergy 1968;42:202-32.

orsyth $\mathrm{K}$, Farmer $\mathrm{K}$, Lennon $\mathrm{BR}$. High admission rate of infants and young children with whooping cough
Aust Pediatr $f$ 1984;20:101-3.

(Accepted 4 April 1985)

\title{
Screening for Down's syndrome using serum $\alpha$ fetoprotein: a retrospective study indicating caution
}

\author{
K SPENCER, P CARPENTER
}

\begin{abstract}
A report was made on the outcome of a four year retrospective study in 27064 pregnancies, of the clinical efficiency, sensitivity, and specificity of a screening programme for Down's syndrome based on reported strategies related to the measurement of maternal serum $\alpha$ fetoprotein. This study identified 27 pregnancies affected by Down's syndrome with a median multiple of the median maternal serum $\alpha$ fetoprotein concentration of 0.82 . This figure is considerably higher than that obtained from previous reports on this subject. With an age related multiple of the median maternal serum a fetoprotein strategy, $30.8 \%$ of Down's affected pregnancies were identified as well as $11.6 \%$ of unaffected
\end{abstract}

\footnotetext{
Endocrinology Laboratory, Department of Biochemistry, Oldchurch Hospital, Romford, Essex

K SPENCER, MSC, MRSC, principal biochemist

P CARPENTER, FIMLS, chief medical laboratory scientific officer

Correspondence to: $\mathrm{Mr} \mathrm{K}$ Spencer.
}

pregnancies. Perhaps a United Kingdom collaborative study should begin to investigate the reasons for such wide population variance in the reports for the median multiple of the median for Down's affected pregnancies. Until such studies are carried out, screening for Down's syndrome based on low maternal serum $\alpha$ fetoprotein concentration is premature.

\section{Introduction}

Last year two reports were published outlining the possibility of screening for Down's syndrome, ${ }^{12}$ based on observations that in pregnancies affected by Down's syndrome the maternal serum $\alpha$ fetoprotein concentrations are lower than in unaffected pregnancies. Merkatz et al first showed a relation between fetal trisomic chromosomal abnormalities and low maternal serum $\propto$ fetoprotein concentrations among 41 affected cases compared with maternal serum $\alpha$ fetoprotein concentrations in a group of normal matched controls. ${ }^{1}$ Similarly Cuckle et al showed that in 61 Down's affected pregnancies the maternal serum $\alpha$ fetoprotein concentration, at 14-20 weeks' gestation was 0.72 multiple of the median for a series of 36652 singleton 
pregnancies not affected by Down's syndrome or neural tube defect. 2 They proposed screening strategies for selecting women for amniocentesis and chromosomal analysis based on serum $\alpha$ fetoprotein concentrations either $\leqslant 0.5$ multiple of the median at 14-20 weeks' gestation or below specified maternal age dependent cut offs. Cuckle et al showed that $21 \%$ of affected pregnancies in which the serum $\alpha$ fetoprotein concentration was $\leqslant 0.5$ multiple of the median would be identified at a cost of screening, by amniocentesis, $5 \%$ of unaffected pregnancies, and with the other strategy $40 \%$ of affected pregnancies would be identified at a cost of screening, by amniocentesis, $6.8 \%$ of unaffected pregnancies.

The data of Cuckle et al have encouraged us to look at our population retrospectively, using various strategies, in an attempt to answer questions concerning the clinical efficiency of such a screening programme.

\section{Methods}

A maternal serum $\alpha$ fetoprotein screening programme for fetal neural tube defects has been in operation in the North East Thames region for the past four years. The programme is centred on eight subregional screening laboratories, all of which measure serum $\alpha$ fetoprotein concentration by radioimmunoassay using the same reagent system and protocol as supplied by the Department of Reproductive Physiology, St Bartholomew's Hospital, London. In our laboratory the assay is controlled by including quality control samples spread randomly throughout each batch, and the between assay precision at two concentrations of $\alpha$ fetoprotein in 54 cases is: mean $36.49 \mathrm{kU} / 1$ (SD 1.38; coefficient of variation $3.78 \%$ ) and mean $117.52 \mathrm{kU} / 1$ (SD 6.19; CV 5.27\%).

The figure shows a typical within and between assay precision profile. Our performance in the United Kingdom national external

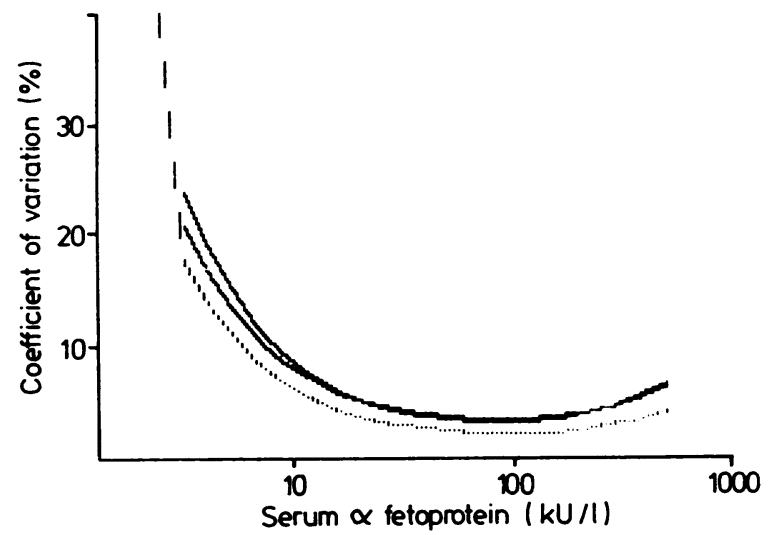

Within assay precision profile for serum $\alpha$ fetoprotein radioimmunoassay. Dotted line is precision of current assay; bold lines are confidence interval for precision profile of past seven assays.

quality assessment scheme shows good precision (variability of bias $4.5 \%$ ), with a bias of $+1.5 \%$ against the all laboratory trimmed mean. The clinical efficiency of this assay at our centre in detecting neural tube defects in a low incidence area (2/1000 births) has been published. ${ }^{3}$ A sensitivity of $97 \%$ for anencephaly and $95 \%$ for open spina bifida was indicated, with an efficacy (the proportion of cases of anencephaly and open spina bifida in the total population that were detected and terminated as a consequence of screening) of $\mathbf{8 8} \%$ and $78 \%$ of the pregnant, screened population.

Pregnancies resulting in termination or the birth of a fetus with Down's syndrome during the years 1980-84 were identified from our screening population from the records of our referral centre at the Department of Cytogenetics, Queen Elizabeth Hospital for Children, Hackney. This search produced 36 cases of Trisomy 21 (Down's syndrome) as determined by fetal or blood karyotyping. Of the affected population, there were 31 live births and five terminations. The number of live births over the screening period was 29540 , which produced an incidence of Down's syndrome of 1/821 births
(1.21/1000). Analysis of the historical records of the $\alpha$ fetoprotein screening service produced 27 results (16-20 weeks) relating to these pregnancies. Two patients went directly to amniocentesis without analysis of serum $\alpha$ fetoprotein, based on advanced maternal age, one was booked after 20 weeks and not screened, and the remaining six had insufficient positive documentation to link the infants' cytogenetic records with those of maternal serum $\alpha$ fetoprotein.

All results of $\alpha$ fetoprotein were expressed in multiples of the median for unaffected pregnancies at the same gestational age. The medians used were those calculated over the whole of the four year screening period, being $36 \mathrm{kU} / \mathrm{l}$ at 16 weeks, $39 \mathrm{kU} / \mathrm{l}$ at 17 weeks, $44 \mathrm{kU} / 1$ at 18 weeks, $51 \mathrm{kU} / \mathrm{l}$ at 19 weeks, and $59 \mathrm{kU} / 1$ at 20 weeks. Gestational age was based on the time since the first day of the last menstrual period in $56^{\circ}$ of of cases and by ultrasonographic biparietal diameter measurement in $44 \%$ of cases.

The data on serum $\alpha$ fetoprotein held on file covering the four year screening period were from 27064 pregnancies. These data were then analysed, based on the following screening strategies, to select mothers at risk of carrying a Down's affected fetus, for which one would suggest amniocentesis and chromosomal analysis. The strategies were: $(a)$ pregnancies in which the serum $\alpha$ fetoprotein concentration was $\leqslant 0.5$ multiple of the median for the gestational age, regardless of maternal age; $(b)$ pregnancies in which the serum $\alpha$ fetoprotein concentration was less than the maternal age dependent cut off concentrations proposed by Cuckle et al for pregnancies in which the maternal age at delivery was under 38 years $^{2}$; and (c) strategy $(b)$ but also including screening by amniocentesis for all mothers aged 38 or over.

\section{Results and comment}

The median multiple of the median maternal serum $\alpha$ fetoprotein concentration for the 27 cases of Down's syndrome was 0.82 (range 0.33-1.59). Mean maternal age was 32.5 (SD 5.6) years, range 24-43; mean maternal height $1.59(0.07)$ metres, range $1.45-1.74$; mean maternal weight $60.6(12.0) \mathrm{kg}$, range $36.4-87.5$; and mean derived blood volume $3 \cdot 1$ litres, range $2 \cdot 20-3 \cdot 97 . .^{4}$ These factors are unlikely to have influenced the serum $\alpha$ fetoprotein concentrations. ${ }^{56}$

Table I outlines the results of the retrospective study using the various screening strategies. Our findings using strategy $(a)$ are compared with those using data from the limited study of Seller ${ }^{7}$ and Cuckle et al. ${ }^{2}$ Our strategy (a) detected $14.8^{\circ}$. of the affected population compared with $12.5^{\circ}$ o with Seller's and $21.3^{\circ}$, with Cuckle et al's. One of the four cases detected in our group, however, would have been selected and detected anyway on grounds of advanced maternal age, as would the only case detected in the study by Seller. To detect $14.8 \%$ of the affected population this scheme would have identified 2321 pregnancies requiring amniocentesis-that is, 8.6\% of the screened population. Given that the risk of normal fetal loss after amniocentesis is $0.5 \%$ in the normal pregnant population, ${ }^{\circ}$ this would result in the loss of 11-12 normal fetuses to detect four affected

TABLE I-Summary of results of four year retrospective study comparing various screening strategies

\begin{tabular}{|c|c|c|c|c|c|c|}
\hline & \multicolumn{6}{|c|}{ Strategy } \\
\hline & (a) & $\begin{array}{l}\text { (a) based } \\
\text { on data } \\
\text { of Seller }\end{array}$ & $\begin{array}{l}\text { (a) based } \\
\text { on data } \\
\text { of Cuckle } \\
\text { et } a l^{2}\end{array}$ & (b) & (c) & $\begin{array}{c}\text { (c) based } \\
\text { on data } \\
\text { of Cuckle } \\
\text { et } \text { al }^{2}\end{array}$ \\
\hline \multirow{9}{*}{$\begin{array}{l}\text { Screening period (years) } \\
\text { No of fetuses with } \\
\text { Down's syndrome } \\
\text { No of fetuses with } \\
\text { Down's syndrome } \\
\text { detected } \\
\text { No of false negatives } \\
\text { No of false positives } \\
\text { No of true negatives } \\
\text { Sensitivity ( } \%) \\
\text { Specificity (\%) } \\
\text { No of amniocenteses as } \\
\text { \%o of screened } \\
\text { population } \\
\text { Normal fetal loss/ } \\
\text { abnormal fetuses } \\
\text { detected }\end{array}$} & 4 & 5 & 8 & 4 & 4 & 8 \\
\hline & 27 & 8 & 61 & 21 & 26 & 61 \\
\hline & & & & & & \\
\hline & & $1^{*}$ & $\begin{array}{l}13 \\
48\end{array}$ & & & $\begin{array}{l}24 \\
37\end{array}$ \\
\hline & 2317 & 470 & 1835 & 1922 & 3119 & 2488 \\
\hline & $\begin{array}{l}24721 \\
14.81 \\
91.44\end{array}$ & $\begin{array}{l}6063 \\
12.50 \\
92.81\end{array}$ & $\begin{array}{l}34776 \\
21 \cdot 31 \\
94.99\end{array}$ & $\begin{array}{l}14408 \\
14 \cdot 29 \\
88 \cdot 23\end{array}$ & $\begin{array}{l}14408 \\
30.77 \\
82 \cdot 18\end{array}$ & $\begin{array}{c}39 \cdot 34 \\
?\end{array}$ \\
\hline & $8 \cdot 6$ & $7 \cdot 2$ & $5 \cdot 0$ & $7 \cdot 1$ & $11 \cdot 6$ & 6.8 \\
\hline & & & & & & \\
\hline & 2.9 & $2 \cdot 4$ & 0.7 & $3 \cdot 2$ & $2 \cdot 0$ & 0.5 \\
\hline
\end{tabular}

(a) is $\leqslant 0.5$ multiple of the median strategy for all age groups. (b) is age related multiple of the median strategy for mothers aged under 38 . (c) is age related multiple of the median strategy for mothers aged under 38 and amniocentesis and karyotyping for those aged 38 and over.

thive mother over 38 years. 
fetuses-that is, a ratio of normal loss/abnormal detection of 2.9 . The comparable ratio with the data of Seller was 2.4 and that of Cuckle et al $0 \cdot 7$.

Table I also summarises our findings using the age related strategy of Cuckle et al for mothers aged under 38 at delivery (column (b)) and the same strategy including the selection of mothers 38 years or older for amniocentesis (column (c)) compared with the data of Cuckle et al. We detected only $14 \cdot 3^{\circ}{ }_{0}$ o of the affected population using the age related strategy alone. This figure was increased to $30.8 \%$ by selecting in addition those patients 38 years or over. The comparable figure from Cuckle et al was $39 \cdot 3^{\circ}$. To detect $30 \cdot 8^{\circ} \%$ of the affected population, however, this scheme would have to identify 3132 pregnancies requiring amniocentesis-that is, $11 \cdot 6^{\circ}$. of the screened population. If the prevalence of loss was $0.5^{\circ}$ this would result in the loss of 15-16 normal fetuses to detect eight affected fetusesthat is, a ratio of normal loss/abnormal detection of $2 \cdot 0$. The comparable ratio using the data of Cuckle et al is 0.5 .

\section{Discussion}

Our study of maternal serum $\alpha$ fetoprotein in 27 Down's affected pregnancies has produced a median multiple of the median considerably higher than that quoted by Cuckle $e t a l^{2}$ or Merkatz et $a l^{1}$ for a group including trisomy $18 \mathrm{~s}, 13 \mathrm{~s}$, and $21 \mathrm{~s}$. Several reports have been published concerning the median multiple of the median for a group of Down's affected pregnancies, ${ }^{7} 9-12$ but little comment has been made concerning the prevalence of false positives with the strategy of Cuckle et al. Table II summarises the published data concerning the median multiple of the median for cases of Down's syndrome. The

TABLE II-Summary of published data on median multiple of the median maternal serum $x$ fetoprotein for cases of Down's syndrome

\begin{tabular}{|c|c|c|c|}
\hline & $\begin{array}{l}\text { Median } \\
\text { multiple of } \\
\text { the median }\end{array}$ & Range & No of cases \\
\hline $\begin{array}{l}\text { Merkatz et al } \\
\text { Cuckle } \text { et } l^{1} \\
\text { Tabor et } a l^{9} \\
\text { Cowchock and Ruch" } \\
\text { Seller } \\
\text { Guibaud } e t a l^{11} \\
\text { Fuhymann } e t \text { al } \\
\text { Chard (personal communication) } \\
\text { UCH (personal communication) } \\
\text { This study }\end{array}$ & $\begin{array}{l}0.65^{*} \\
0.72 \\
0.75 \\
1.00 \\
0.80 \\
0.76 \\
0.80 \\
0.76 \\
0.71 \\
0.82\end{array}$ & $\begin{array}{l}0 \cdot 10-1 \cdot 25 \\
0 \cdot 15-2 \cdot 20 \\
0 \cdot 27-1 \cdot 37 \\
0 \cdot 50-3 \cdot 10 \\
0 \cdot 35-1 \cdot 21 \\
0 \cdot 30-? \\
? \\
0 \cdot 15-1 \cdot 79 \\
0 \cdot 30-1 \cdot 54 \\
0 \cdot 33-1 \cdot 59\end{array}$ & $\begin{array}{l}21 \\
61 \\
25 \\
51 \\
8 \\
43 \\
43 \\
41 \\
25 \\
27\end{array}$ \\
\hline Weighted median multiple of the median & 0.79 & & 345 \\
\hline
\end{tabular}

"Data calculated from figure 4 of paper by Merkatz et al.'

median figure varies among studies, and within the same study the range is often wide. Such varied data from different centres indicate varied population, poor analytical precision, or, more probably, the small numbers used in these studies. The weighted median multiple of the median from all 345 cases is 0.79 .

For the screening strategies proposed by Cuckle et al our study indicates that both the $\leqslant 0.5$ multiple of the median and the age related strategies produce poor discrimination between affected and unaffected pregnancies, detecting only $14.8^{\circ}$, and $30 \cdot 8^{\circ}{ }_{0}$ of affected fetuses, respectively.

The decision to introduce a screening programme for a particular disorder has to balance many factors, including scientific, clinical, financial, organisational, and ethical considerations. ${ }^{13}$ Many would argue, however, that the final assessment must rest with the prevalence of false positives, especially when the patient is being committed to further costly, time consuming, and emotionally traumatic procedures, which in themselves carry a risk, however small, to the fetus. This study shows that the strategies proposed have a high prevalence of false positives.

Currently amniocentesis is indicated as a result of raised serum $\alpha$ fetoprotein concentration in $2.4 \%$ of our screened population, and if all mothers aged 38 and over underwent amniocentesis a further $4.4 \%$ would be screened. Our offer of amniocentesis to all women aged 38 and over would produce a sensitivity of $20 \%$, which is greater than we found for the $\leqslant 0.5$ multiple of the median strategy. The normal fetal loss, given a prevalence of loss of $0.5 \%$ for this "high risk" group, results in a ratio of normal fetal loss/abnormal detection of 1.2.

We concur with Brock ${ }^{14}$ and disagree with Houlsby ${ }^{15}$ that amniocentesis in about $5-6 \%$ of the population is already considered acceptable. Our screening data, however, based on the $\leqslant 0.5$ multiple of the median strategy, would result in amniocentesis for $8.6 \%$, plus the $2 \%$ of screened population already undergoing amniocentesis for raised serum $\alpha$ fetoprotein concentration. This figure for screening for Down's syndrome is almost certainly unacceptable, especially when considered in terms of the ratio of normal fetal loss/abnormal detection of 2.9 for this strategy. Even the age related strategy results in the loss of two normal fetuses to detect one Down's fetus, at a cost of screening, by amniocentesis, $11.6 \%$ of the population. This would mean an increase in workload of $200-400 \%$ for the already overworked cytogenetics service, depending on the strategy used.

Screening by amniocentesis and karyotyping also presents organisational and logistic problems in addition to considerable emotional stress for the pregnant mother, who may wait up to four weeks before a result is available. The move to lower the maximum legal gestational age for termination may result in its reduction to 24 weeks. Clearly if amniocentesis and karyotyping take four weeks then serum $\alpha$ fetoprotein screening has to take place at no later than 18-19 weeks. Several new developments such as the sampling of chorionic villuse ${ }^{16-18}$ and the prescreening of aminopeptidase activity of amniotic fluid ${ }^{14}$ may have a bearing on these problems in the future.

For any laboratory or region considering the introduction of a screening programme for Down's syndrome the message is clear. The current data support the view of Merkatz et al ${ }^{1}$ and Cuckle et $a l^{2}$ that the median multiple of the median serum $\alpha$ fetoprotein concentration in Down's affected pregnancies is significantly lower than that in normal unaffected pregnancies. The various reports on median value for this population, however, make it too premature to consider a screening programme based around the data of Cuckle et al alone. As with neural tube defects, which have a greater incidence than Down's syndrome, we need some form of United Kingdom collaborative study to pool experience and cases before any further action is considered. Indeed, it is surprising that Cuckle et al, who were involved in collaborative studies on neural tube defects, ${ }^{19} 20$ have not suggested this approach. Our greatest concern has been the potentially disastrous effect that such a "high fetal risk, poor affected yield" screening programme might have on our screening of neural tube defects, and the likely erosion of confidence and compliance of patients that might occur.

In conclusion, much is not yet clear about the role, if any, of finding low maternal serum $\propto$ fetoprotein concentration in identifying Down's affected fetuses. It is certainly premature to do anything other than monitor the disorder closely with regional or national studies.

We thank the sisters and staff of the antenatal clinics of Barking, Rush Green, Ilford Maternity, and Harold Wood hospitals for organisational help, Mr L Butler, Cytogenetics Department, Queen Elizabeth Hospital, Hackney, for data on Down's births, and our consultant obstetricians for invaluable discussions concerning these data.

\section{References}

1 Merkatz IR, Nitowsky HM, Macri JN, Johnson WE. An association between low maternal serum alpha fetoprotein and fetal chromosome abnormalities.

Am $\mathcal{J}$ Obstet Gynecol 1984;148:886-94.
2 Cuckle HS, Wald NJ, Lindenbaum RH. Maternal serum alpha fetoprotein measurements: a screening test for Down's syndrome. Lancet 1984;; :926-9. Spencer $K$, Carpenter $P$. Can we afford screening for neural tube defects ? Br Med $1985 ; 290: 711-2$.

adults. Surgery 1962;51:224 T. Prediction of blood volume in normal human 
5 Wald NJ, Cuckle HS, Boreham J, Terzian E, Redman C. The effect of maternal weight on maternal serum alpha fetoprotein levels. Br $\mathcal{f}$ Obstet Gynaecol weight on mate.
$1981 ; 88: 1094-6$.

6 Haddow JE, Kloza EM, Knight GJ, Smith DE. Relation between maternal weight and serum alpha fetoprotein concentration during the second trimester. weight and serum alpha

7 Seller MJ. Prenatal screening for Down's Syndrome. Lancet 1984;i:1359.

8 McNay MB, Whitefield CR. Amniocentesis. Br J Hosp Med 1984;31:406-16.

Tabor A, Norgaard-Pedersen B, Jacobsen JC. Low maternal serum AFP and Down's Syndrome. Lancet 1984;ii:16

10 Cowchock FS, Ruch DA. Low maternal serum AFP and Down's syndrome. Lancet 1984 ; ii: $161-2$.

1 Guibaud S, Bonnet-Capela M, Germain D, Dumont M, Thoulon JM, Berland M Prenatal screening for Down syndrome. Lancet $1984 ;$ i: 1359-60.

( for Down syndrome. Lancet $1984 ;$ ii $: 412$

13 Cuckle HS, Wald NJ. Principles of screening. In: Wald NJ, ed. Antenatal and neanatal screening. Oxford: Oxford University Press, 1984:1-22.
14 Brock DJH. Maternal serum alpha fetoprotein as screening test for Down

15 Houlsby WT. Maternal serum AFP as a screening test for Down syndrome. Lancet $1984 ; \mathrm{i}: 1127$

6 Rodeck $\mathrm{CH}$, Morsman JM. First trimester chorion biopsy. Br Med Bull 1983 39:338-42.

17 Brambati B, Simoni G. Diagnosis of fetal trisomy 21 in first trimester. Lance $1983 ; \mathrm{i}: 586$

18 Lueffler FE. Chorionic villus biopsy. Br 7 Hosp Med 1984;31:418-20.
19 Report of UK collaborative study on alpha fetoprotein in relation to neural tub defects. Maternal serum alpha fetoprotein measurement in antenatal screenin for anencephaly and spina bifida in early pregnancy. Lancet $1977 ; \mathrm{i}: 1323-32$.

20 Second report of the UK collaborative study on alpha fetoprotein in relation to neural tube defects. Amniotic fluid alpha fetoprotein measurement in antenata dragnosis of ane
$1979 ;$ ii $652-62$

Accepted 4 April 1985)

\title{
Comparison of barium swallow and ultrasound in diagnosis of gastro-oesophageal reflux in children
}

\author{
D R NAIK, A BOLIA, D J MOORE
}

\begin{abstract}
Fifty one infants and older children with suspected gastro-oesophageal reflux entered a study comparing the diagnostic accuracy of a standard barium swallow examination with that of ultrasound scanning. All children were examined by both techniques.

In 40 cases there was unequivocal agreement between the examinations. Of the remaining patients, four had definite reflux by ultrasonic criteria but showed no evidence of reflux on barium swallow examination, four had positive findings on ultrasound but showed only minimal reflux on barium swallow, and one showed minimal reflux on ultrasound but had a negative barium meal result. In two children the ultrasound study was inconclusive.

Ultrasound has an important role in the diagnosis and follow up of patients under the age of 5 years with gastro-oesophageal reflux.
\end{abstract}

\section{Introduction}

Gastro-oesophageal reflux is an important and relatively common condition in infancy and childhood. It may be physiological, particularly in the younger age group,' and is self limiting and benign in most cases." It may, however, be one of the causes of failure to thrive, be a cause of repeated chest infections from aspiration, and be a factor in cot deaths. ${ }^{3}$ In addition to radiological means, 24 hour intraluminal oesophageal $\mathrm{pH}$ probe monitoring and isotope scintigraphy have been used for detecting gastro-oesophageal reflux. Recently a method using ultrasound has been described.

We report a study comparing the established method of barium swallow examination with ultrasound scanning in children with suspected gastro-oesophageal reflux.

\footnotetext{
Department of Radiology, Northern General Hospital, Sheffield S5 7AU

D R NAIK, DMRD, FRCR, consultant radiologis

A BOLIA, DMRD, FRCR, senior registrar in radiology

D J MOORE, MB, CHB, senior registrar in radiology

Correspondence to: Dr D R Naik.
}

\section{Patients and methods}

Fifty one children were examined for suspected gastro-oesophageal reflux. Their ages ranged from 4 days to 16 years, though most were under the age of 5 years. The main indications for investigation were vomiting, failure to thrive, repeated chest infections, and near miss infant death syndrome. The examinations were carried out by two operators independently. One operator carried out the barium swallow examination, which was followed later by the ultrasound examination, carried out by the second operator, who had no knowledge of the results of the barium examination. The technique of the ultrasound examination is detailed elsewhere. ${ }^{4}$ Barium swallow examinations were carried out using the standard technique."

\section{Results}

All children were examined by the two methods.

An empty lower part of the oesophagus is shown on ultrasound by three parallel lines, the outer lines representing the two walls and the middle line the collapsed lumen of the oesophagus (fig 1). The fundus of the stomach is easily visualised, being full of the gastric contents. The feed combined with microbubbles of air gives an easily recognisable ultrasonic pattern, comprising the transsonic fluid with scattered, bright speckled echoes representing the microbubbles. These bright echo speckles may be seen moving freely within the stomach.

During gastro-oesophageal reflux the gastric contents with a bright speckled echo pattern of microbubbles may be seen filling the lower oesophagus, when the third of the parallel lines representing the empty lumen will be lost. The two parallel lines will be seen apart from each other and the bright speckled echoes may be seen moving upwards from the stomach (fig 2). Often this is accompanied by "show" at the mouth, confirming the presence of gastro-oesophageal reflux.

Occasional reflux is common in normal children. The criteria used for diagnosing positive reflux were $(a)$ filling of the lower oesophagus on at least two separate occasions, and $(b)$ to and fro movement of the gastric contents between the lower oesophagus and the stomach.

The table gives the results of the barium swallow and ultrasound examinations of the 51 patients. There was agreement in 40 cases, comprising 15 positive, 24 negative, and one minimal positive result. Four patients had definite gastro-oesophageal reflux by ultrasonic criteria but barium swallow did not show any reflux. Four further patients showed positive reflux on ultrasound examination but barium swallow showed minimal reflux. One patient showed minimal reflux on ultrasound examination and had a negative barium swallow result.

There were two older children (13 and 15 years of age) in whom the ultrasound study was inconclusive. In neither case could the gastro-oesophageal junction be visualised. A possible explanation 